\title{
Technical Risk Management for the NGNP Project
}

\author{
Keith J. Perry
}

September 2007

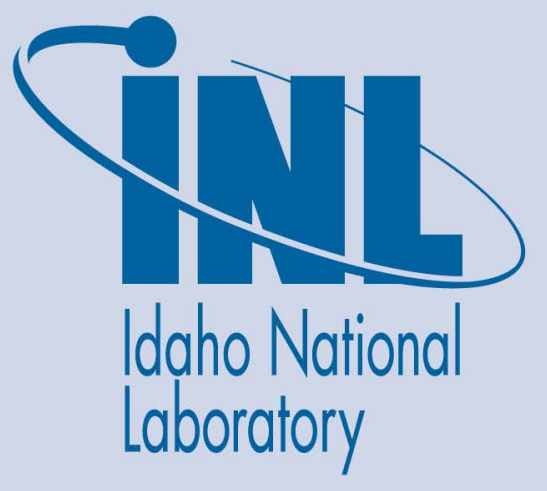

The INL is a U.S. Department of Energy National Laboratory operated by Battelle Energy Alliance 
INL/EXT-07-13148

\title{
Technical Risk Management for the NGNP Project
}

\author{
Keith J. Perry
}

September 2007

\section{Idaho National Laboratory \\ Next Generation Nuclear Plant Project \\ Idaho Falls, Idaho 83415}

Prepared for the

U.S. Department of Energy

Office of Nuclear Energy

Under DOE Idaho Operations Office

Contract DE-AC07-05ID14517 


\section{DISCLAIMER}

This information was prepared as an account of work sponsored by an agency of the U.S. Government. Neither the U.S. Government nor any agency thereof, nor any of their employees, makes any warranty, expressed or implied, or assumes any legal liability or responsibility for the accuracy, completeness, or usefulness, of any information, apparatus, product, or process disclosed, or represents that its use would not infringe privately owned rights. References herein to any specific commercial product, process, or service by trade name, trade mark, manufacturer, or otherwise, does not necessarily constitute or imply its endorsement, recommendation, or favoring by the U.S. Government or any agency thereof. The views and opinions of authors expressed herein do not necessarily state or reflect those of the U.S. Government or any agency thereof. 



\section{Next Generation Nuclear Plant Project}

\section{Technical Risk Management for the NGNP Project}

INL/EXT-07-13148

September 2007
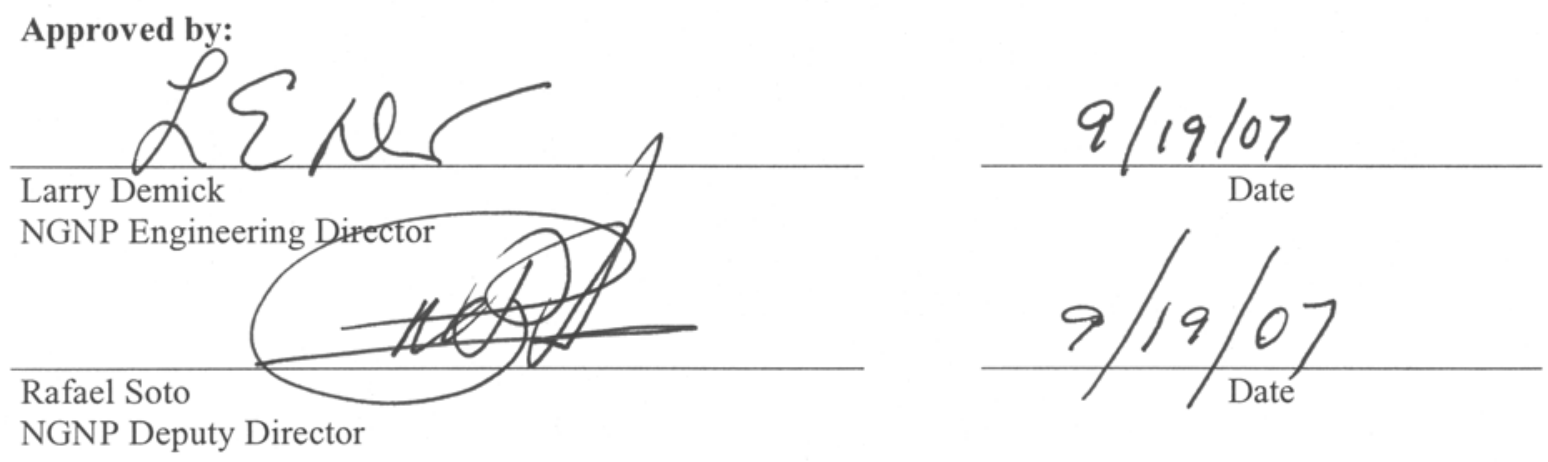



\begin{abstract}
Technical risk management for the Next Generation Nuclear Plant (NGNP) project will incorporate experience from Department of Defense, NASA, and other systems engineering projects. The methodology will be applied to any alternative that is proposed, and is designed to help provide discriminating information for decision-making as well as make each alternative perform at its best by reducing technical uncertainty in a timely manner. A summary of the risk management methodology is provided herein.
\end{abstract}




\section{CONTENTS}

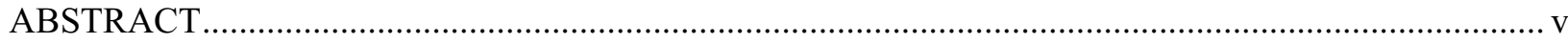

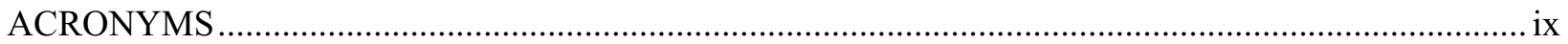

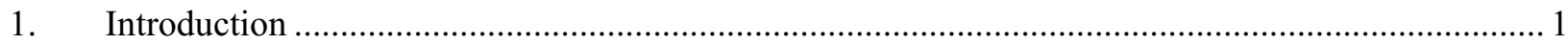

2. Requirements, Goals, and Performance Criteria Definition .................................................... 2

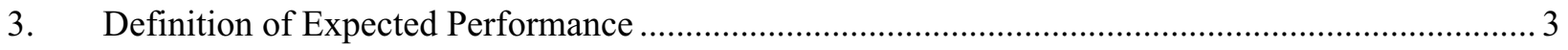

TABLES

Table 1. RPV discriminating criteria and weights [For illustrative purposes only]................................. 3 


\section{ACRONYMS}

DRL Design Readiness Level

GAO Government Accountability Office

NASA

National Aeronautic and Space Administration

NGNP

Next Generation Nuclear Plant

$\mathrm{R} \& \mathrm{D}$

research and development

ROI

return on investment

RPV

Reactor Pressure Vessel

T\&FR

technical and functional requirement

TRL

Technology Readiness Level 


\section{Technical Risk Management for the NGNP Project}

\section{Introduction}

Technical risk management for the Next Generation Nuclear Plant (NGNP) project will incorporate experience from Department of Defense, NASA, and other systems engineering projects. The methodology will be applied to any alternative that is proposed, and is designed to help provide discriminating information for decision-making as well as make each alternative perform at its best by reducing technical uncertainty in a timely manner. A summary of the risk management methodology is provided below, with the remainder of this primer devoted to explaining the details of how the steps would be accomplished. The steps for the risk management are:

- System performance requirements are defined as part of the technical and functional requirements (T\&FRs), and performance goals are defined in concert with performance criteria. In this context, performance criteria and measurements are not limited to physical performance characteristics of the reactor system or its components, but rather performance includes how the system solutions address the mission need and other technical requirements / goals that are not just physical (see example below). The criteria are weighted based on relative importance to the decision-maker.

- Expected performance of the systems is defined based on published data or specific submittals provided by technology providers or subject matter experts.

- The relative maturity of the input is defined based on either a Technology Readiness Level (TRL) scale for technology development related input, or a Design Readiness Level (DRL) scale for design basis related input. Both types of input are often needed for development of discriminating data and risk reduction methodology. The maturity of the systems or component, which directly relates to the maturity of the information about the performance, defines the level of uncertainty for the performance. This information is vital in both understanding the decision-based ramifications and the needs for additional research and development (R\&D) and design development.

- Risk identification tools are used to catalog the known risks associated with the performance of the alternatives. The risks are quantified in terms of how much uncertainty they add to any of the performance factors.

- The performance and uncertainty data are combined to form an overall performance score range for each alternative.

- The performance score ranges are compared to see if there is, in the presence of uncertainty, a risk-informed decision that can be made to either eliminate some alternatives or select a preferred alternative.

- Using the results of the decision analysis, risk reduction plans are defined that both mitigate the known risks as well as increase the maturity of the technology and design, as needed. These plans may include specific R\&D, design development, or other uncertainty reducing activities. The product of this effort is very similar to a normal R\&D plan or schedule. 
- The specific risk reducing and technology / design maturing events are mapped to the risk reduction plan, and the extent to which each risk / maturation is accomplished by the given task is quantified. This allows for development of a risk reduction chart, also known as a risk waterfall chart, which shows how risk can be reduced over time based on expected execution of the risk reduction plan.

- Expected risk reduction can be combined with expected performance measure to evaluate when it is anticipated that future risk-informed decisions can be made. Used iteratively, these charts and data can be used to focus R\&D and design development on tasks that reduce decision uncertainty in the most expedient manner.

\section{Requirements, Goals, and Performance Criteria Definition}

Systems requirements define the minimum system performance. Performance goals describe desired system attributes and are valuable in defining trade-off studies and alternatives discrimination activities. The system owners define both the requirements and the goals; the project can then turn the goals into performance criteria and measures.

For example, the Reactor Pressure Vessel (RPV) must meet a set of safety, containment / confinement, and other performance criteria with respect to the material properties (e.g. the creep temperature of the material shall be above the temperature that the reactor will experience during the high bound of standard operation). Beyond those requirements, there may be aspects of the RPV that are desirable but not required. For example, the expected time needed to qualify the RPV materials of construction for operation should be minimized; the shorter the time, the better the "performance" of that alternative. A criterion could be established called "expected schedule to qualify RPV material." The measure of such a criterion would be duration or time.

Criteria and measures would be set relative to each goal for the system, after which those criteria would be weighted. Weighting is an important part of the process as it establishes the relative importance of the criteria and their impact on the final decision. Given the role of uncertainty in the risk-informed decision (described below), the weighting of the criteria may also drive the emphasis of development work. Criteria weights can be developed by a consensus amongst the decision-makers, or each decisionmaker could provide their own weighting, allowing the development of a base case of criteria weights (the average of the submitted weights) along with room for sensitivity analysis that might explore the bounds of the weights offered by the decision-makers. In either case, the weights are tabulated for later use in developing the combined score for a given alternative.

For illustrative purposes only, Table 1 shows a set of criteria that could be used to rate the performance of RPV alternatives. Table 1 also shows the various weights that results from the use of a Delphi Method, where a team of experts submitted their weights and the average was calculated.

The criteria weights are all fractions, and at various levels the fractions sum to unity. The common levels are represented by the tab level. In the example, the level 1 criteria are related to material properties, design, fabrication and assembly, and operations. Their weights sum to one. For the material properties, the level 2 criteria are related to the max temperature and material codification. The weights of those criteria sum to 0.288 , or the weight of the level 1 criterion. Criteria weights are broken down in this way so that the lowest level criteria are the ones that are actually scored, and those scores can be rolled up to the level 1 criteria. This will be shown in the continuation of the example. 
Table 1. RPV discriminating criteria and weights [For illustrative purposes only].

\begin{tabular}{|c|c|}
\hline Criteria & Weight \\
\hline Material Property Issues & 0.288 \\
\hline Max Temp & 0.155 \\
\hline Emissivity & 0.063 \\
\hline Thermal-mechanical props (Creep) & 0.092 \\
\hline Code & 0.133 \\
\hline In code? & 0.052 \\
\hline$R \& D$ (effort) to get into code & 0.081 \\
\hline Design Issues & 0.191 \\
\hline Size (volume) & 0.109 \\
\hline Thickness & 0.082 \\
\hline Fabrication and Assembly & 0.289 \\
\hline Forging & 0.175 \\
\hline Availability & 0.091 \\
\hline Interest in forging these materials & 0.084 \\
\hline Welding & 0.114 \\
\hline Complexity & 0.055 \\
\hline Heat treatments & 0.022 \\
\hline Methods / procedures & 0.018 \\
\hline Filler metal & 0.014 \\
\hline Experience & 0.059 \\
\hline Operations & 0.232 \\
\hline Environmental Effects & 0.159 \\
\hline Corrosion, impact on emissivity & 0.081 \\
\hline Radiation & 0.078 \\
\hline Repairability & 0.073 \\
\hline
\end{tabular}

\section{Definition of Expected Performance}

Subject matter experts or design and technology providers can identify the expected performance of an alternative with respect to the performance criteria. In each case, literature is required to document the statement of performance and what kind of effort was used to develop the data itself. The data could come from an R\&D activity (e.g., test, experiment), design activity, or previous reactor system experience. The performance must be defined in terms of the criteria measures to allow for criteria scoring.

As the data are gathered, the performance criteria can be scored. Scoring can be qualitative, semiquantitative, or continuously quantitative. Utility theory is used to translate the performance measure into a value between 0 and 1 . In most cases, the translation is linear, meaning a $50 \%$ increase in performance measure translates into a $50 \%$ increase in performance score. However, the decision-maker should 
reserve the right to establish non-linear translations from performance measure to performance score. For example, if R\&D on a given RPV material causes a significant creep performance improvement at ranges well below the temperatures experienced during operations, this would not cause as big a performance score shift as R\&D that shows improvement at or above the temperatures at operation. This scoring system drives the researchers to focus improvement in the areas of greatest impact.

It is important to recognize that at this point of the process the expected performance is what is being scored. The actual performance has some probability of varying from this expected performance due to known risks coming to fruition, unknown risks having an impact, or even revolutionary advances that are not expected to occur between evaluation and deployment. Only the expected performance, supported by some documentation of test results or engineering/science-based estimates, can be used at this point in the evaluation process. Uncertainty around these expectations is managed later in the process and is included in the decision-support documentation.

\section{Identification of Known Risks / Uncertainty}

Risk identification is critical to any project, not to mention one as technically complex as the NGNP. Many excellent templates and texts exist on how to systematically identify risks on a technical development project. That process shall be executed for the NGNP to identify all known risks.

It is understood that the less mature sub-systems and components will have fewer known, but these areas should not be considered "less risky." Risk identification can be compared to a colloquial analogy of a person who wants to buy one of two ships, the first is at the dock, with all of its warts and blemishes readily distinguishable. The other is out at sea, at the very edge of the potential buyer's field of vision. The boat at sea looks pristine and elegant, much better than the boat at the dock. As the second boat approaches the dock, larger problems and issues come into view. When the boat arrives, the buyer is happy they did not make their choice based upon first impressions. Two alternatives of differing maturity can present the same problem, which is why technology and design maturity scales are used to provide an estimate of the potential unknown risks (see below).

Known risks shall be quantified using a probability and consequence scale as found in typical risk management methodology. The higher the product of probability and consequence, the higher will be the risk and associated uncertainty. The uncertainty associated with certain risks must then be applied to the appropriate category, be it alternative performance criteria, project cost, or project schedule. One risk may impact just one area or any combination of areas.

An example of this might be the risk that no supplier desires to fabricate the RPV materials in sufficient size or quantity for NGNP. While this seems initially like a show stopping risk, one mitigation could be for the project to develop material fabrication capability itself. Developing this capability would be both very expensive and very time consuming, probably impacting the critical path of the project. Furthermore, it is not clear whether the newly developed fabrication plant would be more or less able than an existing plant to create the material with the ability to perform as expected in service. Therefore, this known risk could impact all three main areas (performance, cost, and schedule). The extent to which it would impact the areas would need to be traded off, as the impacts are not always independent (e.g., a more costly facility may take more time to build but would allow for better performance characteristics for the material).

A detailed set of known risk was not developed for the example, but rather a combined known/unknown risk level was used and will be explained below. 


\section{Definition of Maturity}

Technical maturity and design maturity are used to estimate the level of unknown risk associated with the performance of a given sub-system or component. The maturity is defined using scales called Technology Readiness Level (TRL) for technology development or Design Readiness Level (DRL) for design basis development. Tables 2 shows the TRL scale adapted for NGNP use, and Table 3 shows the DRL scale developed by the NGNP project.

Table 2. TRL scale.

\begin{tabular}{|c|l|}
\hline TRL & Definition \\
\hline 1 & Basic principles observed and reported \\
\hline 2 & Technology concept and or application formulated \\
\hline 3 & $\begin{array}{l}\text { Analytical and experimental critical function and/or characteristic proof of concept: Lab level for } \\
\text { pieces of components }\end{array}$ \\
\hline 4 & $\begin{array}{l}\text { Lab-scale component validation in lab environment: Demonstrate technical feasibility and } \\
\text { functionality. Beginning of integration of some interfacing components into sub-assemblies }\end{array}$ \\
\hline 5 & $\begin{array}{l}\text { Lab-scale component or sub-assembly validation in relevant environment. Beginning of integration of } \\
\text { sub-assemblies into sub-systems }\end{array}$ \\
\hline 6 & Subsystem model or prototypical scale demonstration in relevant environment \\
\hline 7 & $\begin{array}{l}\text { Subsystem prototype demonstration in an operational environment. Beginning integration of sub- } \\
\text { systems into complete system }\end{array}$ \\
\hline 8 & Total system completed, tested and fully demonstrated and validated \\
\hline 9 & Total system used successfully in project operations \\
\hline
\end{tabular}

Table 3. DRL scale.

\begin{tabular}{|c|l|}
\hline DRL & Definition \\
\hline 1 & Feasibility/Design Initiation $(1 \%-5 \%$ complete $)$ \\
\hline 2 & Preconceptual Design $(6 \%-20 \%$ complete $)$ \\
\hline 3 & Conceptual Design $(21 \%-30 \%$ complete $)$ \\
\hline 6 & Preliminary Design $(31 \%-60 \%$ complete $)$ \\
\hline 10 & Final Design $(61 \%-100 \%$ complete $)$ \\
\hline
\end{tabular}

The scales of maturity allow for a rule of thumb estimation of the overall uncertainty that should be applied to any estimation of performance of a given sub-system or component. For example, if the measure of effectiveness used for evaluation of creep performance for the RPV is said to be at a level that achieves a utility score of 0.7 out of 1 , but the maturity of the sub-system or component only has a TRL rating of a 4 , it is possible that the measure and associated utility score could vary significantly. Perhaps 0.7 is the most likely score at the time of evaluation, but the true score could lie in the range of 0.25 to 0.9. That range should be accounted for in any evaluation of the scores, and this methodology allows for that accounting.

The maturity scales also allow for clearer R\&D and design activity goals to be developed in terms of maturity advancement in addition to goals and activity related to resolving known risks. Any R\&D activity or design activity must be able to answer this question: what known risk will this activity make progress toward resolving or what maturity increase will result from this activity? If there is no answer, then the activity is not increasing the certainty of the performance, cost, or schedule of the project. 
Continuing the for illustrative purposes only example, the RPV for the given designs most likely has a TRL range of anywhere from 4 to 7, depending on if the materials of construction have been tested on their own (e.g., coupons or billets) in relevant environments (e.g., temperatures, fluences), have been integrated with other interfacing components (e.g., reactor core, active cooling systems, if required), and have been fabricated and used at prototypical scale. Some vendors contend that the level is actually an 8 , but no data have been presented to document that the an RPV of this material, size, and interfacing complexity has been fabricated and operated in the appropriate environmental test, all of which is necessary to obtain a TRL level of 8 . The DRL range is smaller, from a 4 to 6 , as the designs have progressed beyond conceptual in nature for the RPVs. Some have moved to initial preliminary design levels, while others are closer to a complete preliminary design.

Maturity evaluations were used semi-quantitatively in an extensive example. A Delphi method was used to query experts on the relative maturity of the given RPV concepts in terms of the decision criteria. Maturity was categorized using a Red, Yellow, Green scale. Red indicated the least mature (least certain), and Green indicated the most mature (most certain). Table 4 shows the relative maturities developed using the Delphi method.

Table 4. Maturities of RPV concepts relative to decision criteria.

\begin{tabular}{|c|c|c|c|}
\hline Criteria & WEC & AREVA & GA \\
\hline \multicolumn{4}{|l|}{ Material Property Issues } \\
\hline \multicolumn{4}{|l|}{ Max Temp } \\
\hline Emissivity & G & G & $\mathrm{G}$ \\
\hline Thermal-mechanical props (Creep) & G & $\mathrm{G}$ & $\mathrm{G}$ \\
\hline \multicolumn{4}{|l|}{ Code } \\
\hline In code? & G & G & G \\
\hline$R \& D$ (effort) to get into code & $\mathrm{Y}$ & $\mathrm{Y}$ & $\mathrm{R}$ \\
\hline \multicolumn{4}{|l|}{ Design Issues } \\
\hline Size (volume) & G & $\mathrm{Y}$ & $\mathrm{Y}$ \\
\hline Thickness & $\mathrm{G}$ & $\mathrm{Y}$ & $\mathrm{Y}$ \\
\hline \multicolumn{4}{|l|}{ Fabrication and Assembly } \\
\hline Forging & $\mathrm{Y}$ & $\mathrm{Y}$ & $\mathrm{Y}$ \\
\hline Availability & $\mathrm{Y}$ & $\mathrm{Y}$ & $\mathrm{Y}$ \\
\hline \multicolumn{4}{|l|}{ Interest in forging these materials } \\
\hline \multicolumn{4}{|l|}{ Welding } \\
\hline \multicolumn{4}{|l|}{ Complexity } \\
\hline Heat treatments & G & $\mathrm{Y}$ & $\mathrm{Y}$ \\
\hline Methods / procedures & $\mathrm{Y}$ & $\mathrm{Y}$ & $\mathrm{Y}$ \\
\hline Filler metal & G & $\mathrm{G}$ & $\mathrm{G}$ \\
\hline Experience & G & $\mathrm{Y}$ & $\mathrm{Y}$ \\
\hline \multicolumn{4}{|l|}{ Operations } \\
\hline \multicolumn{4}{|l|}{ Environmental Effects } \\
\hline Corrosion, impact on emissivity & $\mathrm{R}$ & $\mathrm{R}$ & $\mathrm{R}$ \\
\hline Radiation & $\mathrm{Y}$ & $\mathrm{Y}$ & $\mathrm{Y}$ \\
\hline Repairability & $\mathrm{Y}$ & $\mathrm{Y}$ & $\mathrm{R}$ \\
\hline
\end{tabular}

These values, arrived at purely by expert judgment, form the basis of the uncertainty calculations that occur below. 


\section{Performance Score Range}

With the weighting, utility scoring, and uncertainty calculations in hand, the overall performance score for the alternative can be calculated. Each criterion score gets converted to a score range as the uncertainty impact (per alternative) on that criterion is used.

In the example, the Red, Yellow, and Green scores form the subjective basis of the uncertainty range (in an actual risk management system development, historical data would be used to relate the maturity scores to the uncertainty ranges and, when combined with the uncertainty from the known risks, would form the to uncertainty range). Red equates to $90 \%$ uncertainty, meaning that the score could be as low as $10 \%$ or as high as $190 \%$ of the value calculated from the utility scoring process. Yellow equates to $60 \%$ uncertainty, and Green equates to $25 \%$ uncertainty. Given these values as well as the scores provided using the Delphi method, Table 5 shows the overall comparative results of the RPV alternatives.

Table 5. Overall performance scores and ranges for the three alternatives.

\begin{tabular}{|l|c|c|c|}
\hline \multicolumn{1}{|c|}{ Summary } & High & Medium & Low \\
\hline WEC & 0.69 & 0.28 & -0.12 \\
\hline AREVA & 0.44 & -0.04 & -0.51 \\
\hline GA & 0.17 & -0.37 & -0.91 \\
\hline
\end{tabular}

These values are certainly disputable and are for illustrative purposes only. If they were accurate and substantiated by documentation and data, it would indicate that while WEC's RPV is the highest nominal performer, its lowest level of conceivable performance is lower than the worst alternative's highest level of performance. This overlap indicates that on the basis of decision criteria performance alone, there is no clear cut winner.

In a complete example, the applicable uncertainties would also be applied to the cost and schedule, forming similar high, medium, and low values for those measures for each alternative. It is possible from these data to form graphs that combine the performance uncertainty data with the cost or schedule data. Such a graph for this example could be presented as shown in Figure 1.

Figure 1 does not yield any additional insight to allow for decision making, even for example purposes. However, one can hypothesize the conditions under which a decision could have been made. If the cost uncertainty for the WEC alternative were much lower, say on the order of $\$ 20 \mathrm{M}$ instead of the $\$ 40 \mathrm{M}$ shown, and the GA RPV were nominally $\$ 80 \mathrm{M}$ with a range of $\$ 20 \mathrm{M}$ as well, then the graph in Figure 2 would have resulted.

At least in this hypothetical example there is separation between the alternatives, even though there was no change in the performance range. One might initially jump to the conclusion that the separation allows for a clear decision to be made. That is not entirely the case, as can be explained by the "value lines." The dashed line represents the values of a decision-maker who is cost focused. That person wants a lot of performance for little money. They tend to select acceptably performing, lower-cost alternatives. That person would see a clear separation between these two alternatives and would probably choose to move forward with the WEC RPV. However, a performance focused person, who is willing to spend quite a bit of money to get modest performance improvements and who's values are represented by the solid line, would still see value in keeping the GA alternative on the table, because if it performed at its highest possible range it could out-perform the WEC alternative. For the performance focused decisionmaker, more technical or design work would need to be done to reduce the uncertainty of either or both alternatives before complete differentiation could occur. 


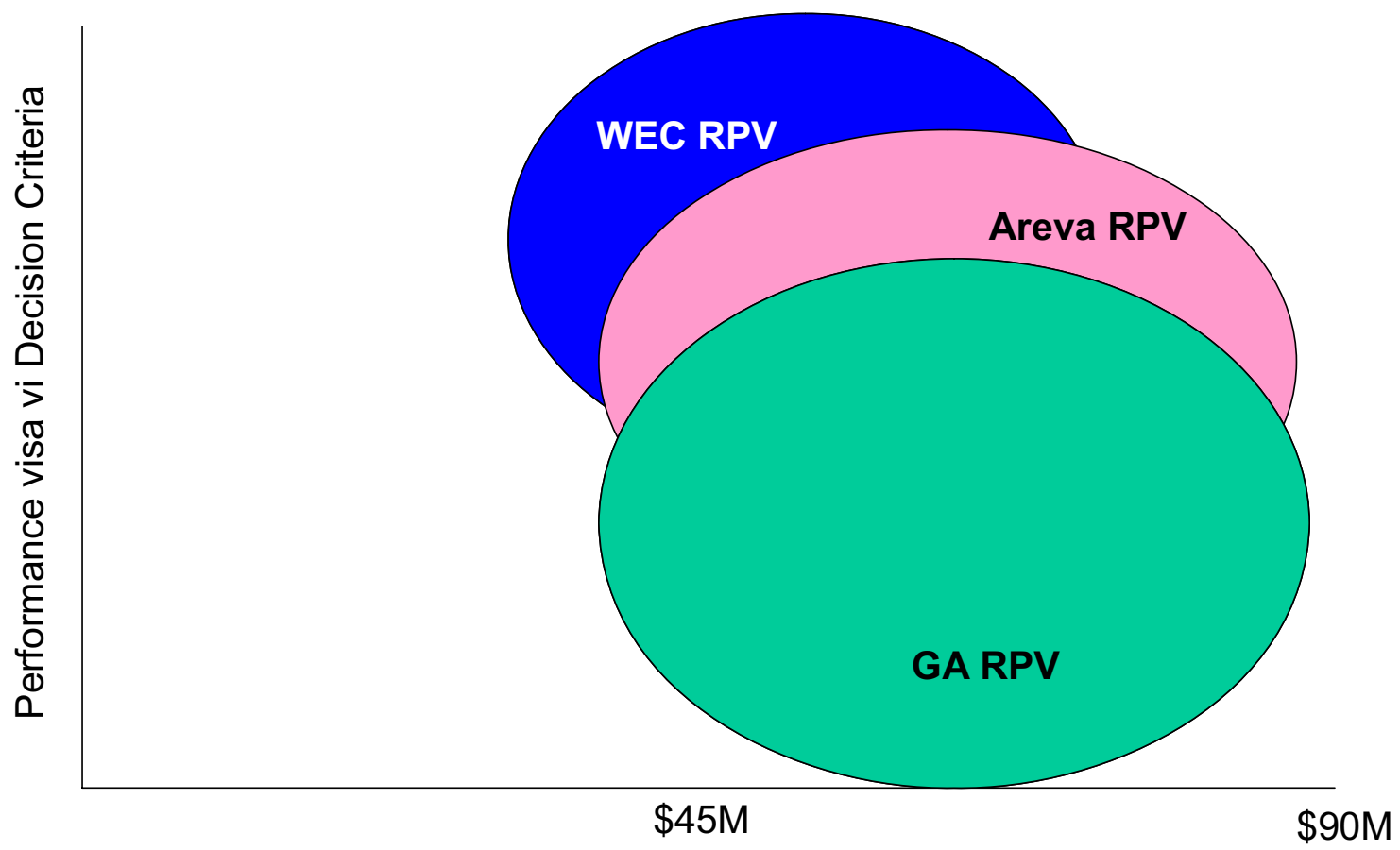

Figure 1. Performance vs. cost graphs.
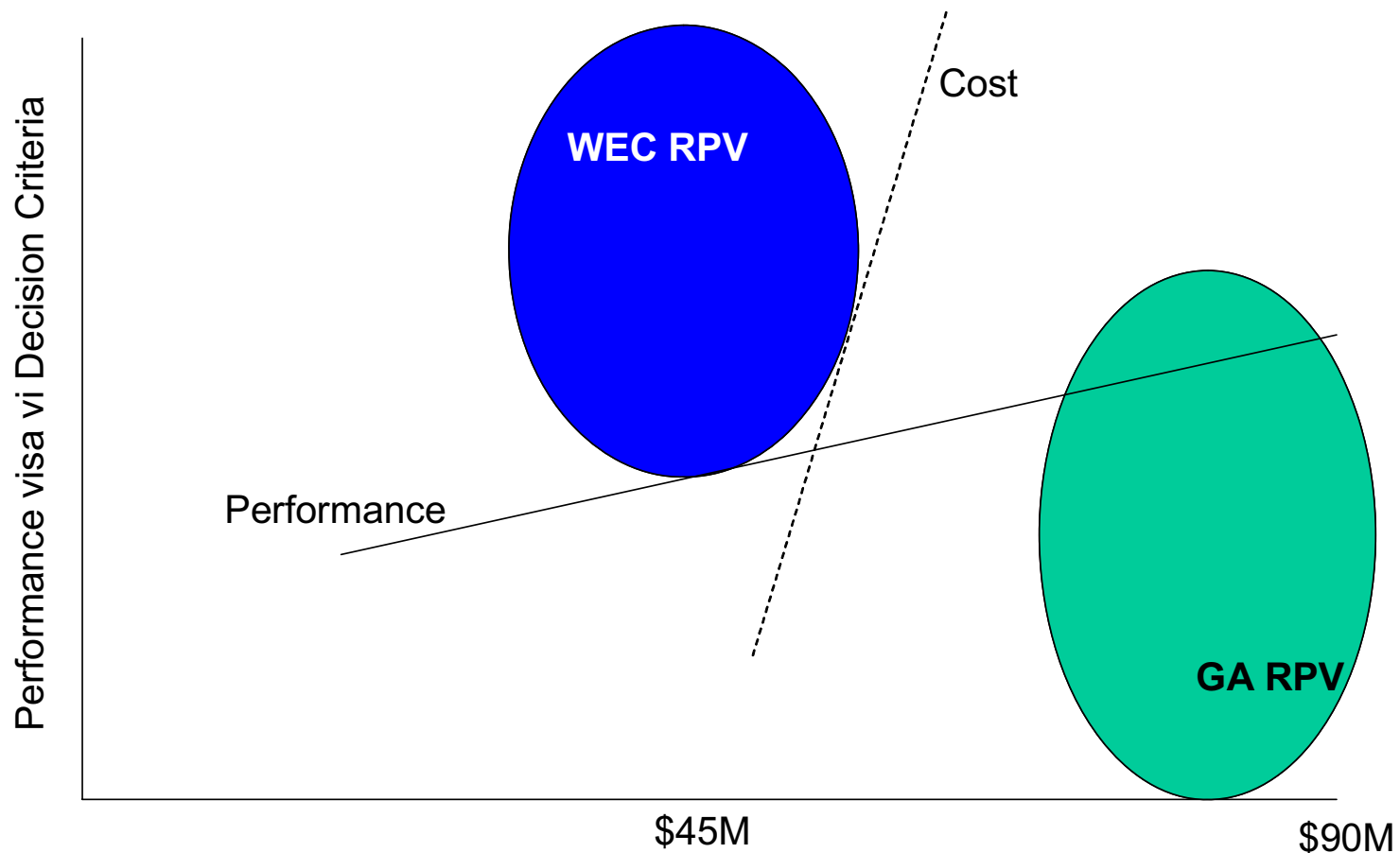

Figure 2. Hypothetical example, reduced cost uncertainty, including value-based lines. 


\section{Risk Reduction Planning}

With the detailed uncertainty, performance, cost, and schedule data, plans can be developed to reduce known uncertainty and increase maturity, providing further differentiation for risk-informed decision making. As describe earlier, each $\mathrm{R} \& \mathrm{D}$ and design task has to be able to specify how they are reducing known uncertainty or increasing maturity. Linkages can be defined between tasks, their outcomes, and the overall uncertainty reduction they provide. This allows for the development of a time phased uncertainty reduction graph, or risk waterfall chart, to be developed. And example is provided in Figure 3.

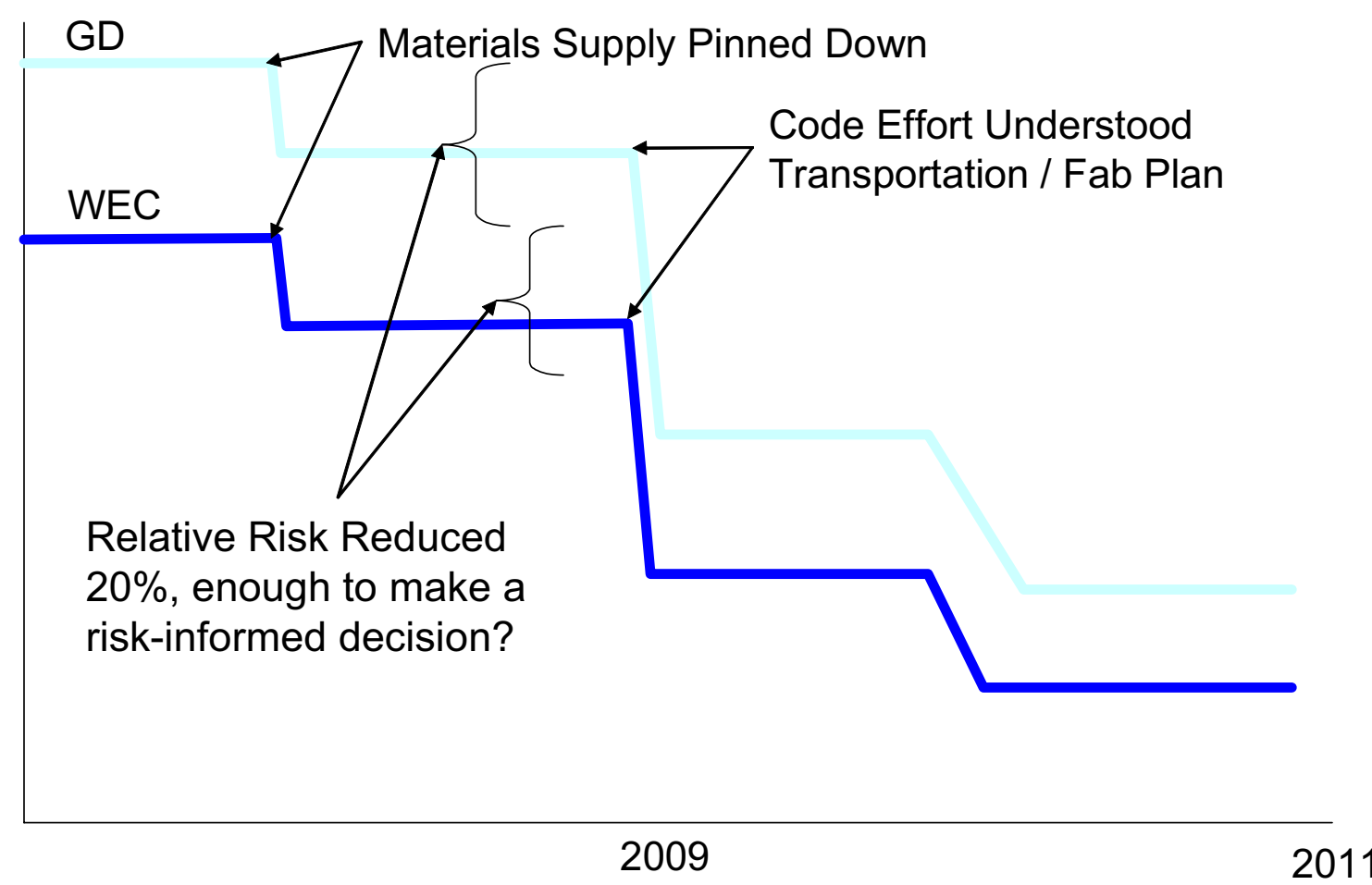

Figure 3. Risk waterfall chart.

These graphs do not show any specific relationship to the nominal performance score for the alternative, but rather how the range of score changes over time if the R\&D and design plans are followed. For example, clarifying who will supply the RPV materials will reduce the overall uncertainty, as will defining the codification effort, transportation plan, and fabrication plan. Understanding these elements may cause the performance of the given alternative to improve, decrease, or remain the same. The same can be said of the cost or schedule basis. Uncertainty reduction does not make the nominal values better, it just makes the project more certain of the likelihood of achieving the nominal values, a vital aspect of decision making as well as cost and schedule planning.

Initially, risk waterfall charts tend to show a back-end-loaded risk reduction process. This is caused by researchers and designers not always being focused on reducing risk and increasing maturity up front. Using the risk waterfall diagram as a feedback tool can improve the prioritization of project work scope and can even provide a return-on-investment (ROI) calculation of sorts (i.e., uncertainty reduction per dollar spent). 
In tandem with risk waterfall charts, performance vs. cost or schedule uncertainty graphs can be used to show when differentiation can be expected in support of a risk-informed decision. Since the waterfall translates to uncertainty reduction, predictions can be made about what the performance vs. cost/schedule uncertainty graphs will look like at certain times. These graphs assume that the nominal performance and cost/schedule values do not change, which is not always the case, but still the graphs can help project management to communicate to the customer an expectation of the duration of the alternative differentiation phase of the project, which can also be helpful in communicating the basis of multi-year funding requests. In any case, these graphs and analysis tools are very powerful in managing risk and developing the basis for risk-informed decisions.

\section{A Note on Risk Reduction for a Single Alternative}

While the above discussion and for illustrative purposes only example focuses on differentiating between multiple alternatives, risk reduction methodologies are important when only one alternative is on the table. Such an effort focuses on reducing uncertainties around the design basis for that alternative, which still improves the ability to predict the nominal cost and schedule needed to complete the project. Performance against decision criteria is no longer important in this scenario and is discarded, but risk management remains. The Government Accountability Office (GAO) emphasized this aspect of risk management recently in their report Department of Energy: Major Construction Projects Need a Consistent Approach for Assessing Technology Readiness to Help Avoid Cost Increases and Delays. They highlight the need to follow just a portion of the process defined here, namely the use of TRLs, to help manage cost uncertainty. This method goes a step further, developing tools and techniques to both manage risk and assure the fastest reduction possible. 